DOI: https://doi.org/10.47405/mjssh.v6i1.643

\begin{tabular}{|c|c|}
\hline 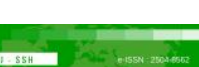 & Malaysian Journal of Social Sciences and Humanities (MJSSH) \\
\hline Malaysian Journal of & Volume 6, Issue 1, January 2021 \\
\hline (MJ-sSH) & e-ISSN : 2504-8562 \\
\hline & $\begin{array}{l}\text { Journal home page: } \\
\text { www.msocialsciences.com }\end{array}$ \\
\hline
\end{tabular}

\title{
Memahami Kronologi dalam Pembelajaran Sejarah Menggunakan Model Pemikiran Sejarah
}

\author{
Siti Kisni Kisson 1 \\ ${ }^{1}$ Universiti Malaysia Sabah (UMS)
}

Correspondence: Siti Kisni Kisson (ctniesk@gmail.com)

\begin{abstract}
Abstrak
Kajian ini meneroka pembinaan Kemahiran Pemikiran Sejarah (KPS) untuk elemen memahami kronologi menggunakan model pemikiran sejarah. Model ini mengetengahkan proses kontekstualisasi dan pengesahan bukti. Dalam kajian ini, model pemikiran sejarah diintegrasikan dengan sumber sejarah dalam bentuk dokumen teks. Dua sumber sejarah berkaitan dengan tajuk perjuangan Mat Salleh menentang pendudukan British di Sabah pada abad ke-19 telah digunakan. Kajian ini menggunakan pendekatan kualitatif dengan reka bentuk kajian kes kolektif. Empat belas orang pelajar dari dua buah sekolah menengah kebangsaan harian di Sabah, menjadi sampel kajian. Kaedah pengumpulan data kualitatif adalah melalui kaedah pemerhatian, temu bual kumpulan berfokus dan analisis dokumen. Didapati majoriti daripada 14 orang pelajar dapat membina elemen memahami kronologi. Elemen memahami kronologi dibina apabila para pelajar dapat menghubungkan persamaan perjuangan pemimpin tempatan di pelbagai tempat dan lokasi. Dapatan lain menunjukkan para pelajar boleh menyusun urutan masa, tarikh dan tahun peristiwa perjuangan Mat Salleh; serta mempelajari peristiwa sejarah tanpa hafalan tarikh dan tahun. Dapatan kajian menunjukkan model pemikiran sejarah dalam pembelajaran menggunakan sumber sejarah dapat membantu para pelajar membina KPS dengan elemen memahami kronologi.
\end{abstract}

Kata kunci: model pemikiran sejarah, elemen memahami kronologi, sumber sejarah, kontekstualisasi, pengesahan bukti

\section{Elements of Understanding Chronology in Learning History Using Historical Thinking Models}

\begin{abstract}
This study explores the construction of Historical Thinking Skills (HTS) for elements of understanding chronology using historical thinking models. This model emphasizes the process of contextualization and corroboration. Historical thinking model were studied using historical sources in the form of text documents. Two historical sources related to Mat Salleh's struggle against the British rule in Sabah in late 19th century were used. Qualitative approach were used with the design of a collective case study. Observation, focus group interviews and document analysis were carried out to collect the data needed. Fourteen students from two national secondary schools in Sabah, Malaysia were selected using purposive sampling. It is found that majority students are able to develop Historical Thinking Skills (HTS) with the elements of chronology in the process of contextualizing and corroboration. This study showed students are able to connect the similarities of the struggle of local leaders in various places. The findings also showed that students are able to arrange the historical event; and learning historical
\end{abstract}


events without memorizing the dates and years. The findings of the study showed that historical thinking model in learning using historical sources, can help students build HTS with elements of understanding chronology.

Keywords: historical thinking model; element of chronology; historical sources; contextualization; corroboration

\section{Pengenalan}

Peranan mata pelajaran Sejarah sebagai pembentuk generasi muda dan masyarakat dalam sesebuah negara tidak dapat dinafikan. Mata pelajaran ini dilihat mampu membentuk masyarakat yang berpengetahuan, memahami warisan sejarah dan mempunyai unsur-unsur perpaduan negara (Twells, 2015). Sejajar dengan peranan mata pelajaran ini, terdapat cadangan agar pembelajaran Sejarah melibatkan kemahiran menganalisis sumber sejarah dilaksanakan. Penggunaan sumber sejarah ini merupakan amalan para sejarawan dalam ilmu sejarah (Burton et al. 2015; Kucan Kucan et al. 2017). Penggunaan sumber sejarah sebagai alat dalam pengajaran dan pembelajaran (PdP) secara tidak langsung memberikan peluang kepada para pelajar memahami peristiwa sejarah seperti seorang sejarawan kecil.

Hal yang demikian, kajian ini meneroka pembinaan elemen memahami kronologi oleh para pelajar dalam PdP Sejarah di bilik darjah. Model pemikiran sejarah (Wineburg, 2010) yang mengetengahkan proses kontekstualisasi (contextualization) dan pengesahan bukti (corroboration) telah diintegrasi dengan penggunaan sumber sejarah. Sumber sejarah yang digunakan dalam kajian ini dalam bentuk penulisan teks. Dua sumber sejarah dengan maklumat berkaitan perjuangan Mat Salleh menentang British di Sabah pada abad ke-19 telah digunakan. Kajian ini melibatkan 14 pelajar Tingkatan Empat dari dua buah sekolah menengah harian di Sabah.

\section{Kajian Literatur}

Dalam pembelajaran mata pelajaran Sejarah di Malaysia, terdapat usaha menekankan kemahiran serta pembangunan intelek untuk mencorakkan Sejarah ke arah pemikiran sejarah. Namun demikian, beberapa kemahiran yang terdapat dalam Kemahiran Pemikiran Sejarah (KPS) dilihat masih gagal dikuasai (Renuka \& Siti Hawa, 2012; Huijgen et al., 2014). Aplikasi KPS didapati masih terhad pada tahap yang asas (Talin, 2014, 2015). Bagi mengubah persepsi dan pemikiran pelajar bahawa mata pelajaran Sejarah membosankan, statik dan tidak menarik (Ambika et al., 2017; Eva, 2018), konsep sejarah dan KPS harus disampaikan (Sarmila \& Abdul Razaq, 2017; Nur Hawa Hanis \& Ghazali, 2018). Justeru, penggunaan sumber sejarah telah diperkenalkan dalam PdP mata pelajaran Sejarah.

Sehubungan itu, penggunaan sumber sejarah melibatkan para pelajar telah menjadi perhatian sejak beberapa lama (Schuette, 2015). Kajian sebelumnya mendapati bahawa terdapat perbezaan penggunaan sumber sejarah oleh sejarawan berbanding para pelajar yang dianggap sebagai novis (Neumann, 2015). Pada masa sama, didapati tidak mudah untuk pelajar memahami sumber sejarah memandangkan ia jarang ditulis untuk tujuan penyiasatan para pelajar (Braasch et al., 2014).

Selanjutnya, kurikulum sejarah di Malaysia menjelaskan tentang pemahaman kronologi sebagai elemen dalam KPS. Kronologi merujuk kepada melihat masa lalu, masa kini dan masa depan mengikut urutan peristiwa bersejarah (Kementerian Pelajaran Malaysia, 2003; Kementerian Pendidikan Malaysia, 2015). Kronologi juga merujuk kepada proses menyusun urutan kejadian atau tindakan bersejarah secara teratur. Umumnya, pemahaman kronologi membolehkan para pelajar memahami secara komprehensif proses peristiwa tertentu dari awal hingga akhir (Mohd Mahzan et al., 2016). Dalam kajian ini, pembinaan KPS untuk elemen memahami kronologi turut diteroka dalam PdP yang menggunakan sumber sejarah. 
Sehubungan itu, pelaksanaan kajian ini adalah selaras dengan amalan disiplin ilmu Sejarah yang perlu disampaikan kepada para pelajar di sekolah menengah (Kementerian Pendidikan Malaysia, 2015, 2018). Pada masa sama, kajian ini, memenuhi matlamat penggunaan sumber sejarah pada peringkat sekolah sebagai alat mempelajari Sejarah (Kaviza; 2018, 2019). Dengan menggunakan sumber sejarah, pembelajaran Sejarah tidak sekadar terikat dengan proses mengingat dan menghafal fakta semata-mata (Wansink et al., 2016). Dengan itu, suasana pembelajaran yang hambar, tidak menarik dan tidak merangsang pemikiran kritis dan kreatif dalam kalangan pelajar (Izhab \& Muhamad Zaid, 2018; Muhamad Yazid, 2018) kemungkinan boleh dielakkan dengan mengaplikasikan amalan ilmu Sejarah dalam pembelajaran mata pelajaran Sejarah.

\section{Model pemikiran sejarah}

Bagi memahami meneroka pembinaan elemen memahami kronologi, model pemikiran sejarah (Wineburg, 2010) mengetengahkan proses kontekstualisasi (contextualization) dan pengesahan bukti (corroboration) telah integrasikan dengan sumber sejarah. Sumber sejarah telah dibaca, dianalisis dan diberikan tafsiran oleh para pelajar dalam proses kontekstualisasi dan pengesahan bukti.

\section{Kontekstualisasi}

Pada dasarnya, kontekstualisasi membantu para pelajar mentafsir sumber dengan memahami masa dan tempat berlakunya peristiwa sejarah tersebut (Kucan et al. 2017). Proses kontekstualisasi turut dikaitkan dengan pemahaman terhadap konteks sosial, ekonomi dan politik (Reisman \& Fogo, 2014). Pada masa sama, proses kontekstualisasi dikaitkan dengan pemahaman pelajar terhadap perbezaan antara masa lalu dan masa kini (Seixas \& Peck, 2004). Untuk kajian ini, proses kontekstualisasi melibatkan tindakan menganalisis sama ada terdapat peristiwa lain berlaku pada masa yang sama dengan peristiwa dalam sumber sejarah (Reisman, 2012). Keseluruhannya, proses kontekstualisasi memberikan pemahaman tentang persamaan dan perbezaan kehidupan masa dahulu dan kini dalam konteks sosial, ekonomi serta politik.

\section{Pengesahan Bukti}

Proses pengesahan bukti melibatkan tindakan membenarkan pembaca sumber sejarah membuat perbandingan pendapat dan maklumat daripada pelbagai sumber maklumat yang ada (Seixas, 2017). Proses ini turut melibatkan para pelajar dengan proses membanding, mencari persamaan atau percanggahan maklumat antara sumber rujukan (Levisohn, 2015) untuk menentukan kebenaran dan kebolehpercayaan fakta yang ditemui (Lund et al., 2017). Umumnya, bagi membuktikan sesuatu maklumat itu benar, ia perlu disokong dengan bukti. Dalam kajian ini, pengesahan bukti melibatkan tindakan menganalisis dan membuat perbandingan maklumat daripada dua sumber sejarah yang disediakan dalam PdP mata pelajaran Sejarah.

\section{Tujuan dan Objektif Kajian}

Kajian ini bertujuan meneroka pembelajaran mata pelajaran Sejarah menggunakan model pemikiran se jarah (Wineburg, 2010) di sekolah menengah harian di negeri Sabah. Objektif kajian ini adalah untuk meneroka pembinaan elemen memahami kronologi dalam proses kontekstualisasi dan pengesahan buk ti (Wineburg, 2010) oleh pelajar-pelajar Tingkatan Empat di Sekolah menengah harian di Sabah.

\section{Metod Kajian}

Untuk kajian ini, pendekatan kualitatif yang menekankan konteks sosial bagi membolehkan informan berkongsi pandangan, pengalaman dan pemahaman mereka secara mendalam (Creswell, 2014) dipilih. Selain itu, pendekatan kualitatif dianggap sesuai kerana kajian ini melibatkan interaksi manusia yang memerlukan penyelidik mentafsir atau memahami amalan manusia secara semula jadi (Mertens, 
2005). Untuk kajian ini, penyelidik menekankan penerangan terperinci tentang elemen memahami kronologi dalam pembelajaran Sejarah.

Seterusnya, tumpuan kepada bagaimana informan pelajar-pelajar memahami dan mempelajari Sejarah dengan model pemikiran sejarah daripada perspektif mereka sendiri, membawa kepada penggunaan kajian kes (Yin, 2014). Dalam kajian kes, penerangan yang kaya tentang subjek daripada peserta kajian adalah penting (Merriam, 2015). Kes kajian ini melibatkan 14 orang informan pelajar yang terlibat dalam sesi PdP Sejarah menggunakan model pemikiran sejarah (Wineburg, 2010). Dalam kajian ini, penyelidik menggunakan kaedah sampel bertujuan.

Selanjutnya, kajian ini melibatkan proses kutipan data yang terperinci dan mendalam daripada sumber pemerhatian, temu bual dan analisis dokumen. Strategi menganalisis data merujuk kepada tiga peringkat: peringkat satu (manual); peringkat dua (koding); dan peringkat tiga (tafsiran data) (Corbin et al., 2014). Penyelidik menjalankan pemerolehan data daripada pemerhatian PdP di bilik darjah. Teknik temu bual kumpulan berfokus, secara tidak berstruktur dijalankan. Akhirnya, analisis dokumen terdiri daripada jurnal pelajar dan hasil kerja bertulis pelajar dijalankan.

\section{Dapatan Kajian}

\section{Menghubungkan Persamaan Perjuangan Pelbagai Pemimpin Tempatan}

Dalam proses kontekstualisasi, para pelajar dapat menganalisis persamaan beberapa peristiwa sejarah yang berlaku di negeri lain. Peristiwa yang berlaku di Sabah dilihat persamaannya dengan beberapa negeri di Tanah Melayu ketika itu. Separuh daripada para pelajar, dapat memahami kronologi peristiwa perjuangan di Sabah yang ada persamaan dengan peristiwa di Tanah Melayu.

Para pelajar mendapati bahawa terdapat beberapa peristiwa di negeri lain yang ada persamaan dengan penjajahan di Sabah. Separuh daripada 14 pelajar ini menyatakan negeri yang terlibat dalam peristiwa menentang penjajahan British secara terperinci. Antaranya, Carol menyatakan bahawa "bukan sahaja Sabah yang tergugat, malahan Perak, Pahang dan Terengganu juga turut tergugat." Rad menerangkan tentang "ada juga peristiwa sama berlaku di negeri lain, di Tanah Melayu." Carl menjelaskan bahawa "ada juga peristiwa sama berlaku. Contohnya di Sarawak dengan penentangan James Brooke."

Pendapat yang sama disokong oleh pelajar-pelajar lain. Antaranya;

"Sama juga penentangan pembesar di Tanah Melayu seperti Mat Salleh. Peristiwa ini boleh disamakan dengan penentangan pembesar Melayu terhadap penjajah British ..." (AD-FEB)

“Pembesar juga mahu pertahankan Tanah Melayu daripada British.” (AD-DEN)

"Mat Salleh adalah seorang pejuang yang menentang penjajahan dan penguasaan orang British. Sama seperti di Tanah Melayu.” (AD-AWG)

Beberapa hasil kerja penulisan berkumpulan menunjukkan catatan tentang “... berlaku perjuangan yang sama di tempat lain, contohnya di Pahang, Terengganu dan Perak...” (AD-K2). Turut dikenal pasti bahawa "berlaku penjajahan British di Tanah Melayu dan Sarawak" (AD-K3).

Kumpulan pelajar yang lain menulis tentang persamaan peristiwa sejarah; "berlakunya peristiwa perjuangan yang sama di tempat lain, contoh Melaka, Naning” (AD-K4). Persamaan dilihat meliputi "penjajahan di Tanah Melayu, penjajahan di Sarawak" dan "perebutan kuasa" (AD-K1). 


\section{Menyusun Urutan Masa, Tarikh dan Tahun Peristiwa Sejarah}

Dalam proses kontekstualisasi, lebih daripada separuh pelajar dapat menyatakan jangka masa berlakunya perjuangan Mat Salleh. Mereka menemui tarikh kedatangan British ke Sabah, permulaan perjuangan Mat Salleh menentang British dan jangka masa yang diambil untuk menentang penjajahan. Majoriti pelajar dapat menyusun urutan masa, tarikh dan tahun peristiwa sejarah yang dipelajari. Dicatatkan tarikh yang berkaitan dengan peristiwa kedatangan Mat salleh ke Sandakan untuk berbincang dengan pihak British pada tahun 1895; tahun 1897 untuk tarikh penubuhan kubu Mat Salleh di Ranau; dan hasrat Mat Salleh hendak bertemu gabenor pada tahun 1899. Carl turut mengulas tentang tahun perjuangan Mat Salleh yang berlaku "pada tahun 1894 hingga 1900 Mat Salleh telah menentang KKBU hampir enam tahun" (AD-CARL). Aziz selanjutnya menghuraikan bahawa pada "akhir sekali, beliau akhirnya tewas dan meninggal dunia pada akhir 31 Januari 1900".

Avil menjelaskan secara lanjut, "pada pertengahan 1894 hingga 1900, terjadi konflik antara Mat Salleh dengan pihak British, iaitu Mat Salleh menentang KBBU" (AD-AVIL). Dengan agak lancar Kin mengemukakan pendapat tentang "... penentangan Mat Salleh berlarutan selama enam tahun, iaitu 1894-1900." Awang membuat kesimpulan bahawa "beliau menentang penjajahan British pada akhir kurun ke-19 hingga awal kurun ke-20" dan "pada tahun 1897 Mat Salleh menubuhkan kubu di Ranau dan menyerang Pulau Gaya” (AD-AWG).

Pendapat yang sama disokong oleh pelajar-pelajar lain. Antaranya:

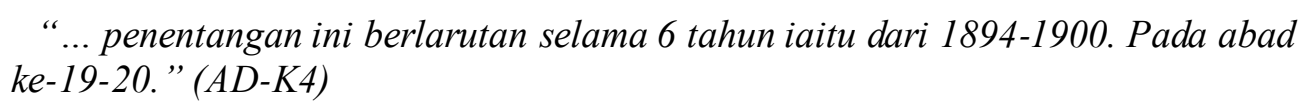

"Dari segi konteks perjuangan beliau berlaku pada abad ke-19 hingga ke-20." (AD-K3)

\section{Mempelajari Peristiwa Sejarah Tanpa Hafalan Tarikh dan Tahun}

Dalam proses pengesahan bukti, majoriti pelajar mempelajari kronologi peristiwa sejarah tanpa perlu menghafal tarikh dan tahun. Mereka dapat mengingati, menerangkan dan mengambil kira tahun serta tarikh penting dalam peristiwa sejarah. Menurut Jo, "tidak perlu hafal semua tarikh dan tahun. Saya boleh cerita tentang Mat Salleh.". Dengan ringkas Feb berkata, "tidak perlu hafalan." Ann menerangkan bahawa "Sejarah bukan tentang fakta saja, tapi boleh tahu bila terjadi."

Awang turut bersetuju bahawa penggunaan sumber sejarah dalam bentuk dokumen teks "bukan menghafallah. Tapi banyaklah tahu tempat dan bila Mat Salleh berjuang." Turut dicatatkan tarikh yang berkaitan dengan peristiwa perjuangan Mat salleh. Hal ini turut disokong dengan pendapat pelajar-pelajar lain.

"Dengan empat proses guna teks lebih baik untuk pembelajaran. Kajian tentang Mat Salleh dapat ingat. Tahun dan bila berlaku." (Sid)

"Pada pendapat saya lebih mudah daripada mencari satu persatu maklumat tersebut ... sebab kita lebih memahami tentang perjuangan Mat Salleh. Tahun bukan paksa hafal." (Den)

"Lebih baik untuk memahami daripada penghafalan buku teks kerana lebih mudah ... kerana tidak mudah lupa, dan kita lebih faham daripada menghafal." (Rad)

\section{Perbincangan Dapatan Kajian}

Dapatan kajian menunjukkan majoriti pelajar dapat menganalisis persamaan beberapa peristiwa yang berlaku di tempat lain dengan proses kontekstualisasi. Para pelajar memahami bahawa peristiwa 
sejarah tidak hanya melibatkan peristiwa dipelajari. Peristiwa yang berlaku dapat disokong dengan peristiwa sejarah di tempat lain. Mereka dapat menghubungkan peristiwa sejarah dalam konteks masa yang sesuai dengan peristiwa perjuangan Mat Salleh di Sabah. Tema, tahun dan tarikh berlaku penjajahan di Sabah dihubungkan dengan peristiwa sama di tempat lain. Dapatan kajian ini mengukuhkan dapatan De La et al. (2016) bahawa pelajar boleh mentafsir maklumat sumber sejarah dengan memahami masa dan tempat berlakunya peristiwa sejarah tersebut.

Selanjutnya, proses kontekstualisasi membolehkan para pelajar menjelaskan bahawa konteks peristiwa perjuangan Mat Salleh melibatkan pemahaman terhadap elemen kronologi. Para pelajar dapat menganalisis masa, tahun, tarikh dan lokasi sesuatu kejadian perjuangan Mat Salleh berlaku. Dapatan kajian ini menyokong cadangan Van Boxtel dan Van Drie (2012) agar pembelajaran Sejarah harus menyediakan pelajar dengan peluang mengamalkan kontekstualisasi.

Dalam proses pengesahan bukti, elemen pemahaman kronologi peristiwa sejarah memudahkan para pelajar menjelaskan dan menerangkan maklumat yang ditemui. Para pelajar menemukan catatan pelbagai tarikh dan tahun tanpa perlu menghafalnya. Dapatan kajian ini bertentangan dengan kajian Blow et al. (2012) yang menunjukkan pelajar menghadapi kesukaran menguasai asas dalam memahami kronologi.

Keseluruhannya, dapatan kajian menunjukkan para pelajar telah mempelajari sejarah perjuangan Mat Salleh di Sabah melalui proses kontekstualisasi dan pengesahan bukti. Penemuan kajian ini menunjukkan elemen kronologi dapat dikuasai oleh majoriti pelajar. Dapatan kajian turut menunjukkan para pelajar mampu memberikan pendapat tentang perjuangan pemimpin tempatan menentang penjajah. Mereka memahami bahawa peristiwa perjuangan zaman penjajahan dahulu, akhirnya membentuk negara pada hari ini. Para pelajar dapat menghubungkan kronologi perjuangan negara pada masa dahulu ada hubungan dengan kebebasan masyarakat pada masa kini. Dapatan kajian ini sejajar dengan dapatan Rusen (2012) yang menyimpulkan bahawa memahami kronologi akan membangunkan kesedaran sejarah dengan menunjukkan kesepaduan antara mentafsir masa lalu dan memahami masa kini.

Hal yang demikian, model pemikiran sejarah (Wineburg, 2010) dapat membantu pembinaan elemen memahami kronologi. Justeru, penggunaan model pemikiran sejarah oleh Wineburg (2010) dengan integrasi sumber sejarah memberikan para pelajar peluang membina KPS. Dapatan kajian ini menepati dapatan kajian Demers et al. (2015) bahawa penggunaan sumber sejarah boleh menjadi titik memulakan pemikiran sejarah para pelajar. Dapatan kajian ini turut menyokong kajian Hickman (2014) tentang penggunaan sumber sejarah yang dapat meningkatkan keupayaan dalam pemikiran bersejarah.

\section{Kesimpulan}

Pembelajaran Sejarah menggunakan model pemikiran sejarah (Wineburg, 2010) yang diintegrasikan dengan sumber sejarah membantu para pelajar membina pemikiran bersejarah. Konsep KPS dapat merangsang pemikiran pelajar dengan memahami kronologi. Penemuan kajian ini turut menunjukkan para pelajar boleh berinteraksi dengan sumber sejarah; melibatkan aktiviti seperti membaca, menganalisis dan mentafsir maklumat dokumen teks sebagai proses skema minda. Justeru, penggunaan sumber sejarah dalam pembelajaran memperkenalkan kepada para pelajar tentang sifat sebenar sejarah yang perlu dianalisis dan ditafsirkan.

Sehubungan itu, melalui sesi pembelajaran yang berulang-ulang, para pelajar memperoleh ilmu pengetahuan secara aktif dan membolehkan mereka membina elemen memahami kronologi. Sejarah tidak lagi disampaikan dengan menekankan fakta semata-mata. PdP mata pelajaran Sejarah lebih aktif dan lebih dinamik kerana kepelbagaian pendapat oleh para pelajar tentang peristiwa sejarah, tokoh, dan masyarakat. Oleh yang demikian, proses PdP sedemikian membolehkan kurikulum terus berkembang dalam memenuhi keperluan pelajar mempelajari mata pelajaran Sejarah. Pemahaman peristiwa masa lalu diperoleh seiring dengan proses pembinaan elemen memahami kronologi. 


\section{Rujukan}

Ambika Luhitadati, Maskun \& Suparman Arif. (2017). Hubungan motivasi berprestasi dengan hasil belajar Siswa pada mata pelajaran sejarah. Jurnal Pendidikan dan Penelitian Sejarah, 5(8),1-12.

Blow, F., Lee, P., and Shemilt, D. (2012). Time and chronology: Conjoined twins or distant cousins? Teaching History, 147, 26-34.

Braasch, J. L., Bråten, I., Strøms $\varnothing$, H. I., and Anmarkrud, Ø. (2014). Incremental theories of intelligence predict multiple document comprehension. Learning and Individual Differences, 31, $11-20$.

Burton, E. P., Pellegrino, A., and Gallagher, M. (2015). Humanizing the disciplines: Historical thinking and students' understanding of the nature of science. The Georgia Social Studies Journal, 5(1), 54-67.

Corbin, J., Strauss, A., \& Strauss, A. L. (2014). Basics of Qualitative Research. Sage Publications.

Creswell, J. W. (2014). A concise introduction to mixed methods research. Sage Publications.

De La Paz, S., Monte-Sano, C., Felton, M., Jackson, C., Piantedosi, K.W., \& Croninger, R.A. (2016). 'A historical writing apprenticeship for adolescents: Integrating disciplinary learning with cognitive strategies'. Reading Research Quarterly, $0(0), 1-22$.

Demers, S., Lefrançois, D., \& Ethier, M. A. (2015). Understanding agency and developing historical thinking through labour history in elementary School: A local history learning experience. Historical Encounters, 2(1), 34-46.

Eva Budi Effila. (2018). Upaya meningkatkan motivasi belajar sejarah siswa XIII PA1 SMA Negeri 1 Pasir Penyu melalui penggunaan media film dokumenter. Jurnal Pendidikan Tambusai, 2(4), 606-618.

Hickman, K. D. (2014). What were they thinking? Primary sources and perspective taking in social studies instruction. Studies in teaching 2014, Research Digest, 37.

Huijgen, T., Van Boxtel, C., Van de Grift, W., \& Holthuis, P. (2014). Testing elementary and secondary school students' ability to perform historical perspective taking: The constructing of valid and reliable measure instruments. European Journal of Psychology of Education, 29,653672.

Izhab Ismail \& Muhamad Zaid Ismail. (2018). Hubungan kemahiran pemikiran sejarah dengan amalan guru dalam proses pengajaran dan pembelajaran sejarah. Prosiding seminar kebangsaan majlis dekan pendidikan universiti awam 2018, November 7-8, 2018. Universiti Sultan Zainal Abidin, hlm. 303-320.

Kaviza, M. K. M., Rahim, F. A., \& Bukhari, N. (2018). The relationship between readiness of learning based historical sources towards intrinsic motivation. Jurnal Pendidikan Bitara UPSI, 11(1), 52-63.

Kaviza, M. (2019). Analisis keperluan terhadap pembangunan modul aktiviti pengajaran dan pembelajaran sejarah berasaskan sumber-sumber sejarah. e-Bangi. Journal of Social Science and Humanities, 16 (6), 1-11.

Kementerian Pendidikan Malaysia. (2003). Sukatan pelajaran KBSM sejarah (semakan).Kuala Lumpur: Dewan Bahasa dan Pustaka.

Kementerian Pendidikan Malaysia. (2015). Dokumen standard kurikulum dan pentaksiran mata pelajaran sejarah tingkatan satu. Putrajaya: Bahagian Pembangunan Kurikulum.

Kementerian Pendidikan Malaysia. (2018). Kurikulum standard sekolah menengah sejarah, dokumen standard kurikulum dan pentaksiran tingkatan 4 dan 5. Putrajaya: Bahagian Pembangunan Kurikulum.

Kucan, L., Cho, B. Y., \& Han, H. (2017). Introducing the historical thinking practice of contextualizing to middle school students. The Social Studies, 108 (5), 210-218.

Levisohn, J. A. (2015). Historical thinking - and its alleged unnaturalness. Educational Philosophy and Theory, 1-13.

Lund, E. S., Bråten, I., Eva, W., Brante, E. W., \& Strømsø, H. I. (2017). Memory for textual conflicts predicts sourcing when adolescents read multiple eExpository texts. Reading Psychology, 0, 121.

Merriam, S. B. (2015). Qualitative research: Designing, implementing, and publishing a study. In P. A. Hershey. Handbook of research on scholarly publishing and research methods (pp. 125-140). IGI Global. 
Mertens, D.M. (2005). Research and evaluation in education and psychology. Sage Publications.

Muhamad Yazid Khalil. 2018. Tahap pengetahuan guru Sejarah sekolah rendah dalam kemahiran pemikiran sejarah. Paper presented at National Innovation and Invention Competition through Exhibition (I-Complex), 20-23 March, Politeknik Sultan Abdul Halim Muadzam Shah, Kedah.

Neumann, F. (2015). How does a historian read a scholarly text and how do students learn to do the same? In D. Ludvigsson \& A. Booth (Eds.), Enriching history teaching and learning, challenges, possibilities, practice (pp. 51-66). Linköping University.

Nur Hawa Hanis Abdullah \& Ghazali Darusalam. (2018). Kesediaan guru melaksanakan kemahiran kemahiran berfikir aras tinggi dalam pengajaran. Jurnal Kurikulum \& Pengajaran Asia Pasifik, 6(2), 22- 31.

Reisman, A. (2012). 'Reading like a historian: A document-based history curriculum intervention in urban high schools'. Cognition and Instruction, 30(1), 86-112.

Reisman, A., \& Fogo, B. (2014). Teaching disciplinary history in secondary history classes. In M. Hougen (Ed.), The Fundamentals of literacy assessment and instruction (pp. 6-12). Brookes Publishing Co.

Renuka Ramakrishnan \& Siti Hawa Abdullah. (2012). Penggunaan sumber digital sejarah dalam kalangan guru Sejarah. Seminar Kebangsaan Majlis Dekan Pendidikan IPTA 2012, 7-9 Oktober 2012. Universiti Teknologi Malaysia

Sarmila Tamoh Deram \& Abdul Razaq Ahmad. (2017). Pembangunan Modul 5E dalamn meningkatkan kemahiran pemikiran sejarah. Kertas kerja yang dibentangkan di 2nd International Conference in Education and Regional Development, 20-21 November 2017.Bandung, Indonesia.

Schuette, L. (2015). Researching the historical representations of ancient Egypt in trade books. Eastern Illinois University.

Seixas, P., and Peck, C. (2004). Teaching historical thinking. Challenges and Prospects for Canadian Social Studies, 109-117.

Talin, R. (2014). An investigation of the teaching and learning practice of History in secandary schools: A case study. International Conference on Education and Social Sciences Prosiding, 3-5 February 2014. Istanbul Turkey.

Talin, R. (2015). Historical thinking skills-The forgotten skills? International Journal of Learn and Teaching, 7(1), 15-23.

Twells, A. (2015). 'More than gaining a mark': Students as partners and co-producers in public history and community engagement. In D. Ludvigsson \& A. Booth (Eds.), Enriching history teaching and learning, challenges, possibilities, practice (pp. 51-66). Linköping University.

Van Boxtel, C., \& Van Drie, J. (2012). "That's in the time of the Romans!" Knowledge and strategies students use to contextualize historical images and documents. Cognition and Instruction, 30 (2), 113-145.

Wansink, B. G. J., Akkerman, S., \& Wubbels, T. (2016). The certainty paradox of student history teachers: Balancing between historical facts and interpretation. Teaching and Teacher Education, $56,94-105$.

Wineburg, S. (2010). Thinking like a historian. Teaching with Primary Sources Quarterly, 3(1), 2-5.

Yin, R. L. (2014). Case study research: design and methods ( $5^{\text {th }}$ edition). Sage. 